\title{
Caryophyllaeid infestations on the sex and size of Walking Catfish Clarias batrachus
}

\author{
MS Chhanda and KJ Chandra* \\ Department of Aquaculture, Bangladesh Agricultural University, Mymensingh 2202, Bangladesh
}

\begin{abstract}
An investigation was carried out on the caryophyllaeid infestations in walking catfish Clarias batrachus in relation to different sexes and size groups during August 2010 to July 2011. A total of 227 host fish were collected from different water bodies of Mymensingh for examination. Among them $188 \mathrm{C}$. batrachus were infested with 1432 parasites by five different caryophyllaeid cestodes species. Prevalence was $100 \%$ during November and December both in male and female hosts. In other period of the year, female were more infested. In male fishes, the highest intensity and abundance were recorded in December and index of infection in February. In female fishes, the lowest infestations were recorded during the months of August, September and October. Parasites showed different levels of infestations in different size groups of fishes. Higher prevalence was recorded in medium size fishes in winter and summer and smaller size fishes in autumn. However, the index of infestations and abundance were higher in same size group only in winter season. The lowest prevalence and mean intensity were recorded in rainy season and abundance was in summer in smaller size group of fish.
\end{abstract}

Key words: Cestode infestation, sexes, size groups, Clarias batrachus

Bangladesh Animal Husbandry Association. All rights reserved. Bang. J. Anim. Sci. 2011.40 (1-2): 56-59

\section{Introduction}

The Clarias batrachus is a highly demanded and expensive fish species among freshwater fishes of Bangladesh. It is popularly known as Magur and is liked by everybody for its delicacy and food value. However, the fish is infested by caryophllaeid cestodes severely.

Parasite is an important factor in fisheries and aquaculture for causing diseases and in many cases responsible for fish mortality. Cestode represents a highly diversified group of exclusively parasitic of agriculture and veterinary importance with unique morphology and complex life cycles (Caira and Littlewood 2001). Caryophyllaeid is a special group of cestode with elongated body, devoid of segmentation and proper scolex or holdfast organ. This parasite is particularly infesting the silurid fishes like Clarias batrachus and Heteropneustes fossilis in Bangladesh (Chandra 1993). Considerable damage and pathological changes have been recorded by several authors (Amlacher, 1961; Mackiewicz and Murhar 1972; Agarwal 1985) in infested hosts. Chandra et al. (1997) studied the association and development of Lytocestus indicus from Clarias batrachus in Mymensingh. These parasites utilize oligochaetes as inter- mediate hosts to complete their life cycle, through which they finally accumulate in the host intestine. However, the process of infesting fish host is complex and variable in respect of size, sex and even season of the year. On preliminary investigation (Rashid et al. 1983) indicated this variation of infection in $C$. batrachus. The present work therefore initiated for detail understanding the nature of caryo-phyllaeid infestation in Clarias batrachus in relation to sex and size of host.

\section{Material and Methods}

Host fish, the C. batrachus was collected from different water bodies like beels, haors, rivers, farms and fish markets of Mymensingh. They were brought to the fish disease laboratory of Aquaculture Department for parasitic investtigation. In the laboratory total length ( $T L$ ) and sex of the fish were recorded. The host fish was classified into three different length groups of $20>, 20-23$, and $23<\mathrm{cm}$. The study period was divided into four different seasons as summer (March-May), rainy (June-August), autumn (September-November) and winter (DecemberFebruary)

The host fish was anaesthetized and opened ventrally for collection of parasites. The parasites 


\section{Caryophyllaeid infestations on walking catfish}

were kept in normal saline for relaxation, alcohol. Some of the fixed specimens were prepared in glycerin jelly for clearing and others were made permanent slides staining in alum carmine, dehydrated in alcohol grades, clearing in lactophenol and mounted in Canada balsam.

Infestations were analyzed according to Margolis et al. (1982) as i) Prevalence (\%) = Percent of infestation of a host species, ii) Mean intensity = Number of parasites per infested host, iii) Abundance $=$ Number of parasites per examined host, and iv) Index of infection =

No. of parasites collected x No. of infested hosts No. of hosts examined

\section{Result and Discussion}

Total 227 fish were examined. Among them 188 C. batrachus were infested with 1432 parasites of five different caryophyllaeid cestodes species. They were (i) Djombangia peretrans (ii) Lytocestus indicus (iii) Lytocestus birmanicus (iv) Lytocestus parvulus and (v) Bovienia serialis (Chhanda 2011). The infestation in the host fish were found to vary with sexes and size groups of the host fishes.

\section{Infestation in different sex of host}

Infestation due to caroyphyllaeid cestodes in male and female host showed differences. In general, the prevalence were higher in female $(93.33 \%)$ but the higher rate of mean intensity (6.98), index of infection (53.49) and abundance (6.45) were found in male fishes. During August, September and October, all male host were infested. However, both male and female fishes were found infested in rest period of the year. Prevalence was $100 \%$ during November and December both in male and female hosts (Table 1 ). The other period of the year female were more infested i.e., $100 \%$ prevalence were indicated from November to June. The highest intensity and abundance were recorded 25.83 in December and index of infection 56.8 in February from male fishes. Infestations were also presented to show the sex wise variations by flattened and fixed in formalin, acetic acid and caryophyllaeid cestodes of $C$. batrachus in different seasons (Table 2). It was observed that prevalence were $100 \%$ in winter and summer in the female fishes. However the mean intensity was higher in summer (15.22), Index of infection in winter (89.27) and abundance in autumn (15.75) in male fishes of $C$. batrachus. On the other hand the lowest prevalence was $33.33 \%$ in autumn and mean intensity were 4.24 in winter in female fishes. In case of seasonal distribution the prevalence and intensity of infestation of $C$. batrachus indicated that there were significant differences $(p<0.05)$ among different sexes.

In the present study the infestation was higher in male fish than the females. The male fish may be more susceptible to parasitic infestation. Higher infestations in female fish were however reported by several authors (Chandra et al. 1997; Rashid et al. 1983). Skorping (1980) reported significant difference $(p<0.05)$ in prevalence and mean intensity in male and female hosts. Sanaullah and Ahmed (1978) did not find conspicuous variation in infection in different sex. Aloo et al. (2004) stated that the main reason for the differences in parasitic load with sex is physiological. It might be related to the feeding habits of the host that means male fed more than female fishes of $C$. batrachus.

\section{Infestations in different size groups of host}

The hosts were infested with caryophyllaeid cestode in all size groups. Parasites had also found different levels of capacity of infestation in different size groups of fish. The variation of infestation in different size groups were presented in Table 3. Higher rate of prevalence $(100 \%)$ was recorded in medium size fishes in winter and summer and smaller size fishes in autumn. The intensity and abundance also recorded (19.37) higher in medium size group fish in winter season. The lowest prevalence $(23 \%)$ and mean intensity (1.67) were recorded in rainy season and abundance (3.73) were in summer in smaller size group. Differences of infestations among different size groups of host were found significant $(p<0.05)$. 
Chhanda and Chandra (2011) Bang. J. Anim. Sci. 40 (1\& 2): 56-59

Table 1: Infestation of caryphyllaeid cestode parasites in C. batrachus during August to July 2011

\begin{tabular}{|l|cc|cc|cc|cc|c|c|}
\hline \multirow{2}{*}{ Months } & \multicolumn{2}{|c|}{$\begin{array}{c}\text { No. fish } \\
\text { Examined/infested }\end{array}$} & \multicolumn{2}{|c|}{$\begin{array}{c}\text { Prevalence } \\
(\%)\end{array}$} & \multicolumn{2}{|c|}{ Mean intensity } & Index of infection & Abundance \\
\cline { 2 - 13 } & Male & Female & Male & Female & Male & Female & Male & Female & Male & Female \\
\hline August $/ 10$ & $10 / 10$ & $0 / 0$ & 100 & - & $2.1^{*}$ & - & 21 & - & 2.1 & - \\
September /10 & $12 / 12$ & $0 / 0$ & 100 & - & $9.75^{*}$ & - & 117 & - & 9.75 & - \\
October /10 & $15 / 9$ & $0 / 0$ & 60 & - & $1.56^{*}$ & - & 8.4 & - & 0.93 & - \\
November/10 & $12 / 12$ & $6 / 6$ & 100 & 100 & $5 *$ & $22.5^{*}$ & 60 & 135 & 5 & 22.5 \\
December/10 & $6 / 6$ & $10 / 10$ & 100 & 100 & $25.83^{*}$ & $2.6^{*}$ & 155 & 26 & 25.83 & 2.6 \\
January/11 & $10 / 8$ & $12 / 12$ & 80 & 100 & $8.75^{*}$ & $6.33^{*}$ & 56 & 76 & 7 & 6.33 \\
February/11 & $15 / 12$ & $5 / 5$ & 80 & 100 & $5.92^{*}$ & $3.8^{*}$ & 56.8 & 19 & 4.73 & 3.8 \\
March/11 & $4 / 3$ & $16 / 16$ & 75 & 100 & $2 *$ & $3.69 *$ & 4.5 & 59 & 2 & 3.68 \\
April/11 & $9 / 9$ & $11 / 11$ & 100 & 100 & $10.67^{*}$ & $3.82^{*}$ & 96 & 42 & 10.67 & 3.82 \\
May/11 & $12 / 6$ & $8 / 8$ & 50 & 100 & .33 & $2.63^{*}$ & 1 & 21 & 0.17 & 2.63 \\
June/11 & $8 / 8$ & $12 / 12$ & 100 & 100 & $7.38^{*}$ & $4.25^{*}$ & 59 & 51 & 7.38 & 4.25 \\
July/11 & $10 / 4$ & $20 / 8$ & 40 & 40 & $4.5^{*}$ & $8.75^{*}$ & 7.2 & 28 & 1.8 & 3.5 \\
\hline Total & $127 / 99$ & $100 / 88$ & 82.92 & 93.33 & 6.98 & 6.49 & 53.49 & 50.77 & 6.45 & 5.90 \\
\hline
\end{tabular}

$* p<0.05)$

Table 2: Infestation of caryphyllaeid cestode parasites in $C$. batrachus in different seasons during August 2010 to July 2011

\begin{tabular}{|l|cc|cc|cc|cc|}
\hline & \multicolumn{2}{|c|}{ Summer } & \multicolumn{2}{c|}{ Rainy season } & \multicolumn{2}{c|}{ Autumn } & \multicolumn{2}{c|}{ Winter } \\
\cline { 2 - 10 } & Male & Female & Male & Female & Male & Female & Male & Female \\
\hline Prevalence (\%) & 75 & 100 & 80 & 46.67 & 90 & 33.33 & 86.67 & 100 \\
Mean intensity & $15.22 *$ & $3.38^{*}$ & $4.66^{*}$ & $4.33^{*}$ & $5.39 *$ & $7.5^{*}$ & $13.5^{*}$ & $4.24^{*}$ \\
Index of infection & 33.83 & 40.67 & 26.07 & 26.33 & 61.33 & 45 & 89.27 & 40.33 \\
Abundance & 4.28 & 10.13 & 3.76 & 2.58 & 15.75 & 7.5 & 12.52 & 4.24 \\
\hline
\end{tabular}

$* p<0.05)$

Table 3: Seasonal variation of infestation of caryophyllaeid cestode in different length groups of $C$. batrachus during August 2010 to July 2011

\begin{tabular}{|l|cccc|cccc|ccc|c|}
\hline Size & \multicolumn{3}{|c|}{ Prevalence (\%) } & \multicolumn{4}{c|}{ Mean intensity } & \multicolumn{3}{c|}{ Abundance } \\
\cline { 2 - 13 } group & Summer & Rainy & Autumn & Winter & Summer & Rainy & Autumn & Winter & Summer & Rainy & Autumn & Winter \\
\hline$>20$ & 87 & 23 & 100 & 75 & $4.31^{*}$ & $1.67 *$ & $5.89 *$ & $5.83^{*}$ & 3.73 & 0.38 & 5.89 & 4.19 \\
$20-23$ & 100 & 76 & 93 & 100 & $4.90^{*}$ & $5.23 *$ & $14.57 *$ & $19.37 *$ & 4.90 & 4.20 & 13.6 & 19.37 \\
$23<$ & 83 & 81 & 55 & 96 & $3.85 *$ & $6.06 *$ & $2.40^{*}$ & $12.54 *$ & 3.21 & 4.95 & 1.33 & 12.04 \\
\hline
\end{tabular}

There were different reports on the variation of infestation in different size of fishes. The infestations of $C$. batrachus were higher in middle length class group, and which was more or less similar to the other findings (Chandra, 1998; Kennedy 1970; and Ahmed and Sanaullah 1977). The present finding was in agreement with of Rashid et al. (1983, 1985) who reported higher infestation in medium size group fishes. Dogiel (1964) reported that the prevalence and intensity of infestations increased with the age of fish hosts. As the size increased the fish ate more and the carrying capacity increased to support more parasites. Stromberg and Crites (1975) observed prevalence and intensity of infection generally increased with host size up to a point and then declined. This may be happened for maximum food intake with the development of their body and sexual maturity.

\section{Conclusion}

It may be concluded from the present investigation that $C$. batrachus may be affected by caryophyllaeid cestodes and infestation of parasite was found to vary with sexes and size groups of fish. Present investigation also revealed 


\section{Caryophyllaeid infestations on walking catfish}

the nature and pattern of infestation in relation to sexes and size of host which may help for control measures of this parasite for successful Clariid culture.

\section{Acknowledgement}

The authors thank UGC for financial support in the form of granting a research project through which the present work was conducted.

\section{References}

Agarwal SM (1985). Caryophyllaeids and Caryophyllaeidiasis in India. Ind. Rev. Life Sci. 5: 139-161.

Ahmed ATM and Sanaullah M (1977). Observation on the incidence and intensity of infestations of some helminthes in different length groups of Heteropneustes fossilis (Bloch) and Clarias batrachus (L.). Dhaka Univ. Stud. 25: 91-98.

Amlacher E (1961). "Traschenbuch der fischkrank-heiten" Gustav Fischer Verlag, Jena. P. 286.

Aloo PA, Anam RO and Mwagni JN (2004) Metazoan parasites of some commercially important fish along the Kenyan Coast, Western Indian Ocean. J. Mar. Sci. 3: 7178.

Caira JN and Littlewood DTJ (2001). Worms, Platyhelminthes. Encycl. Biodiver. Vol. 5. Academic Press. San Diego, California. p. 863-899.

Chandra KJ (1993). Helminth parasites of certain freshwater and estuarine fishes of Bangladesh. BAU Res. Prog. 7: 643-654.

Chandra KJ (1998). Seasonal biology of Procamallanus heteropneustus Ali, 1957 in fish stinging catfish Heteropneustes fossilis of Mymensingh, Bangladesh. Bang. J. Aquacult. 20: 7-14.

Chandra KJ, Islam KZ and Wootten R (1997). Some aspects of association and development of Lytocestus indicus Moghe in catfish Clarias batrachus (Lin.). Bangladesh J. Fish. Res. 1: 31-38.

Chhanda MS (2011). Seasonal infestations of caryophyllaeid cestodes in Clarias batrachus
(Linnaeus, 1758) of mymensingh. M.S. thesis, Department of Aquaculture, Bangladesh Agricultural University, Mymensingh, Bangladesh. P. 49.

Dogiel VA (1964). General Parasitology. (English Translation). Edinburgh and London: Oliver and Boyd.

Kennedy CR (1970). The population biology of helminths of British freshwater fish. P. 145159. In: Aspects of Parasitology. (A.E.R. Taylor and R. Muller, eds.) Blackwell Sci. Pub., Oxford and Edin. P. 167.

Mackiewicz JS and Murhar BM (1972). Redescription of Bovienia serialis (Bovien, 1926) (Cestoidea: Caryophyllaeidae) from the catfish Clarias batrachus (L.) in India. J. Helminth., 46: 399-405.

Rashid MM, Haque AKM and Chandra KJ (1983). Records of some metazoan parasites of Clarias batrachus (Linnaeus) from Mymensingh. Bangladesh J. Fish. 6: 37-42.

Rashid MM, Haque AKM and Chowdhury MBR (1985). Population dynamics of Caryophyllaeid cestodes parasitizing Clarias batrachus. Bang. J. Agril. Sci. 12: 179-174.

Margolis L, Sch GW, Holmes JC, Uris AM and Chad GA (1982). The use of ecological terms in Parasitology. J. Parasit. 68(1): 131-133.

Sanaullah M and Ahmed ATA (1978). Observation of some aspects of association in the parasitic infection in the catfishes Heteropneustes fossilis (Bloch) and Clarias batrachus (L.) of Bangladesh. Bangladesh J. Fish. 1: 73-84.

Skorping A, (1980). Population biology of nematode Camallanus lucustris in perch, Perca fluviatilis L., from an oligotrophic lake in Norway. J. Fish Biol. 16: 483-492.

Stromberg PC and Crites JL (1975). Popultation biology of Camallanus oxicephalus Ward and Magath, 1916 (Nematoda: Camallanidae) in white bass in western Lake Erie. J. Parasit. 61: 123-132. 